\title{
Silo foundation optimization through reinforcement concrete shell structure
}

\author{
C. J. Martins ${ }^{1}$, O. A. Figueiredo ${ }^{1}$, L. A. Martins ${ }^{2}$ \\ \& R. A. F. Peixoto ${ }^{1}$ \\ ${ }^{I}$ Department of Civil Engineering, CEFET/MG, Belo Horizonte, $M G$, \\ Brazil \\ ${ }^{2}$ Geological Survey from Brazil - CPRM Regional Bureau, \\ Belo Horizonte, MG, Brazil
}

\begin{abstract}
The objective of the present work is to perform a technical and economic analysis of the adoption of shell as a structural solution for the foundation of industrial vertical silo. Initially projected in a rigid and flat slab, the foundations of a vertical silo were optimized by numerical computational modeling through a parallel Finite Element Method code, adopting shell in the form of reversed cone. It will be shown that a significant reduction of structural concrete of steel was obtained with the optimization of the silo foundations, and by this way, economy in the execution of the structure.
\end{abstract}

Keywords: non-linear analysis, constructive systems, finite element method, foundations in shell, parallel computing.

\section{Introduction}

Initially, the Foundation Engineering study based itself on empirical observations of the structural and ground behavior of the infrastructure elements. Over 30 years, analytic theories of soil behavior were being developed and improved, being able to be cited, among others, the works developed by Terzaghi and Frolich [1], Skempton and MacDonald [2] and Taylor [3]. With the advent and solid application of the numerical computational approaches (as by example, Finite Element Method, Finite Differences and Boundary Elements), complex models for soil-structure iteration simulation have been conducted to 
more detailed analysis and structural designs, and by this way, for more rational foundations (Kurian [4]).

Among the several structural elements used for foundations of constructions, applicable to most soil types, the concrete floor is a method of shallow foundation that has many advantages when specified and correctly implemented. Overall, concrete floors are massive slabs that support and distribute, in a uniform way, the loads of buildings to ground. Given its simplicity of execution and relatively low tension transferred to the ground, it has been widely used in both residential (Martins et al. [5]) works as industrial (Kurian [6]).

To resist the loads from the superstructure acting perpendicular to your plan, in a flat foundation arise internal forces of bending and shear. By another way, in shell foundations (such as the hypar shells) internal forces due superstructure loads provide only internal forces in your plan, mainly tensions compression and in-plane shear (Flugge [7]). This difference in behaviour implies a structural optimization in the dimensioning of the shell foundations, since the material is subject mainly to internal forces of normal compression. The economy of material becomes more evident when such elements of foundation are made of structural concrete, whose high performance under action of internal forces of compression provides a great reduction in consumption of material.

The modern concept of using shells as structural elements of foundations is being addressed by researchers worldwide. Candela can be considered as the forerunner of art, introducing foundations of paraboloid hyperbolic shells in the soil of the city of Mexico (Candela [8]). Over the years, many works addressing studies and applications of shell foundations were developed. Kurian [9] presents a feasibility study of these foundations. Hanna and Abdel-Rahman [10] researched the behavior of conical shell settled under sand. Maharaj [11] and Martins et al. [5] analyzed the behavior of these foundations in clay, by nonlinear Finite Element Method. Nicholls and Izadi [12], Melerski [13], Kurian [6] studied the bearing capacity of foundations in paraboloid hyperbolic form. Kurian and Varghese [14] and Kurian and Mohan [15] analyzed the distributions of the contact tensions of foundations in shell. Harrop-Williams and Grivas [16], Chandrashekhra and Antony [17] analyzed the interaction between foundations in non-homogeneous elastic soil. Melerski [13] developed an approached solution for the problem of the shell of small thickness resting on elastic base. Kurian [18] discusses the applicability and advantages of the use of shells as elements of foundation. The evident economic benefits from the use of shallow foundation in the form of shells are proven in several reports of applications in various parts of the world (Kurian [6]). In general this technique shows great reduction of consumption of materials and consequent increase in complexity in the work of excavation. As reported in the literature, the foundations in shell are extremely advantageous when they are submitted in at least one of the following situations: low carrying capacity of the land or cost of the workforce relatively low in comparison to the cost of materials (steel reinforcement and structural concrete).

The use of shallow foundations made in structural reinforced concrete in the form of shells, in particular the shell in chop-conical geometry, as element of 
foundation for a set of vertical circular silo with $30.000 \mathrm{t}$ of capacity, situated in a region whose soil presents relative low bearing capacity, is proposed in this work, aiming at reducing the overall costs of the structure. For this, analyses by FEM on cluster of PCs were conducted, taking into account the non-linearity of the concrete and soil. The maximum internal forces, obtained by these analyses, were used in the design of concrete and steel reinforcement sections. Finally, the reduction in materials quantitative obtained from the adoption of the chopconical shell is presented.

\section{Foundations in conical shell geometry}

\subsection{Geometrical aspects}

Although a variety of shells adjust themselves to be used in coverage, those ones that can be used in foundation are few. Among these, there is the chop-conical surface, whose geometric characteristic allows this shell to be used efficiently and effectively in foundations under different circumstances (Kurian [6]). The rotationally symmetrical conical foundation in reinforced concrete, shown in Figure 1(a), is probably the simplest way in which a shell can be put to use in foundations. The placement of the bars is as simple as for flat foundation, while construction is only a little more difficult. The shell may be of uniform thickness, or it may be of varying along its depth. Cones of substantially larger dimensions can also serve as foundations for tall structures such as chimneys, instead of conventional circular or octagonal rafts (Figure 1(b)). The shell of inverted position in Figure 2(a) is appropriate for structures such as guyed Masts. Large inverted conical shells, in their full form or truncated, depending on the required area of contact with the soil, can also be used like foundation for cylindrical structures such as silos and storage tanks grounded (Figure 2(b)).

\subsection{Constructive aspects}

The simplicity in the materialization of the surface of the foundation in conical shell is one of the main characteristics that make the use of this structure economically viable. The sequence constructive is the same that conventional flat foundation, that is: excavating and preparing the soil, positioning of steel bar, casting of concrete. In the following these steps are described. For details see Kurian [6].

\subsection{Design aspects}

\subsubsection{Structural behavior}

Internal forces developed in conical shell structures are much smaller than conventional flat foundations, since this one must resist to bending inner forces by the presence of moments. By another way, the cracks of the concrete structures are almost eliminated in the shell, reducing the risk of corrosion of reinforcement by exposure to moisture from soil. Since shell structures generally are subject only to traction and compression stress, which are always distributed 
at cross sections in a uniform way, resulting in better use of the materials and consequently with economy.

\subsubsection{Geotechnical behaviour}

In general, the geotechnical behavior of the foundations in curve structure has been analyzed in a similar way to the foundation plans structures, adopting itself to the model of Winkler-Pasternack for soil (Maharaj [11]) or through the discretization of soil (Martins et al. [19]). Experimental and theoretical studies have been conducted, whose performance of the structures in shells has presented superior performance than flat ones. Nicholls and Izadi [12] held an experimental research on shell footing with the purpose of determining the distribution of pressure of contact as a function of the ultimate load. The results indicate that ultimate bearing capacity and support displacement for shell structures presented better results when compared with their corresponding conventional flat. Kurian and Varghese [14], by experimental results, confirmed that the use of shell elements leads to more economic structures. Hanna and Abdel-Rahman [20] studied the geotechnical behaviour of shell footings placed over sand and under conditions of axial loading. The results show the admirable performance of foundations shell with respect to ultimate bearing capacity and displacements. In this work, the numerical modelling of the behaviour geotechnical for shell structures was conducted considering soil as a perfectly elastoplastic material and Mohr-Coulomb criteria, considering a parallel implementation of FEM code. As it will be seen, the geotechnical behavior of shop-conical shell presented results seemed flat one.

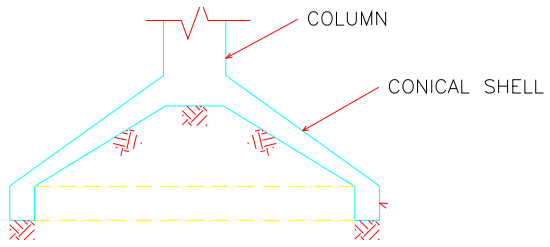

(a) Column footing

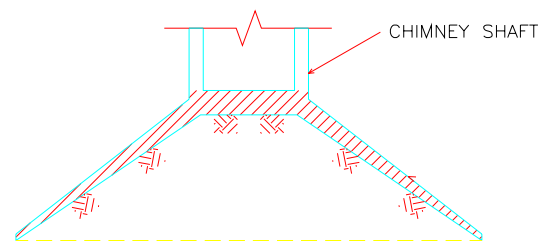

(b) Chimney raft

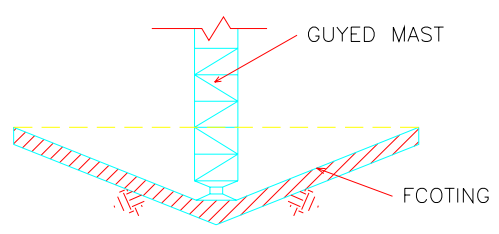

(a) Footing for mast

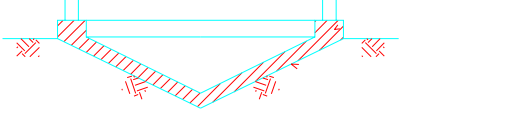

(b) Raft for ground tank

Figure 1: Conical shell foundations. Figure 2: Inverted cone foundations. 


\section{Numerical modeling by FEM}

The finite element method (FEM) is one of the most widely considered computational tools used in solving physical problems. Initially developed aimed at analyzing problems of structural engineering Aeronautics is currently widely used in all areas of Science. The basic idea of numerical analysis by FEM is the subdivision of the field of physical problem with subdomains where the behaviours of the problem is easily represented. It is not intended to calculate the displacement of all points in the subdomains of the structure, such as analytical solutions. In a first instance are calculated only the field variable of some points which are named the nodes of model. Thus, the analyses in these individual subdomains are made and then they are interconnected, simulating the physical problem as a whole. This way it is performed an approximation of the physical response of the real problem, which is more or less close to the exact solution, depending, among other factors, the number of subdomains used in the representation of the physical problem.

One of the reasons for which the method of finite elements succeeded since the beginning of its formulation until today is that its basic concept, the subdivision of the area, produces many simultaneous algebraic equations, which are generated and resolved with the help of digital computers. Thus, you can use standard procedures, for subdomains, which do not involve engineering decisions during the computational procedure. All decisions are taken by the analyst in the stage of assembling the model, before beginning the analysis, choosing the size, arrangement and appropriate element that represents a given physical situation. Hence the idea of the element is very well defined, that is, their mathematical formulation adequately represents the physical behaviour that is intended to simulate.

The numerical modelling via FEM of concrete structures and the layers of soil under the building, were model considering material perfectly elastoplastic (Mohr-Coulomb criteria, Lemaitre and Chaboche [21]). For the FEM analyses that have been conduced here, since that discretization of soil leads to analyses of large degree of freedom, have been used up resources of parallel processing through cluster of PCs, considering paradigm of domain decomposition.

\section{Industrial application}

With the objective of optimizing a vertical circular silo foundation (capacity of storage 1, diameter of 1 and height 1 ), initially designed like flat plan concrete structure, was proposed the adoption of a conical shell foundation. The definition of the geometry of this shell was conducted from a FEM serial numerical modeling by means of commercial software, simulating soil behavior like elements of spring (Winkler's model). Figure 3 presents geometry of silo, taking into account the flat plan foundation initially designed (Figure 3(b)) and the shell foundation proposed in this work (Figure 3(a)). 
From the geometry defined initially (Figure 4) and to the appropriate forecast of geotechnical behavior for soil-silo interaction, the structural system was modeled using computational code based on 3D parallel FEM elastoplastic, using prismatic Lagrangian elements of 21 nodes, with a maximum size of 0.4 meters. The simulation of the ground as a semi-infinite medium was obtained by truncating the model is 16 meters deep and 150 meters at horizontal directions.

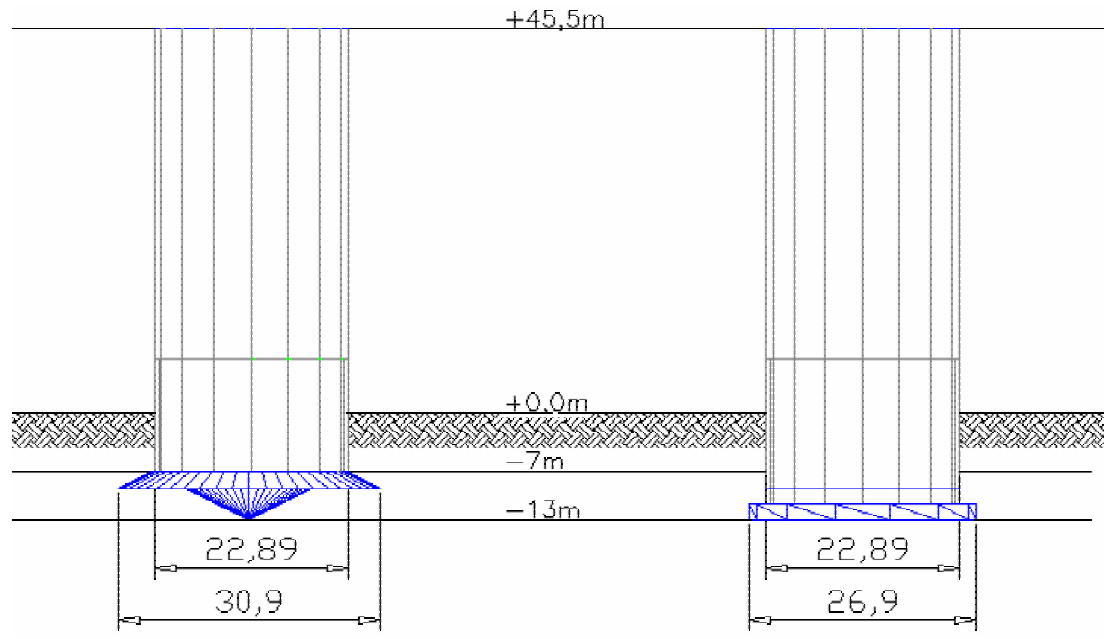

(a) foundation in shell

(b) flat foundation

Figure 3: Geometry of the granary and foundations (units in meter).

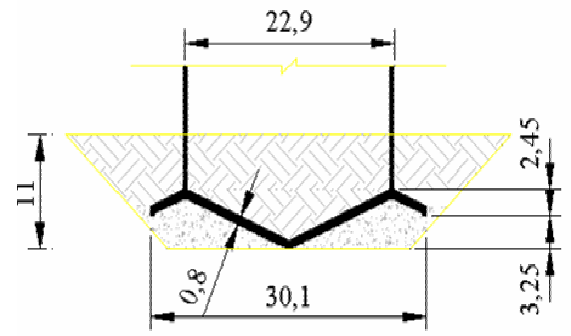

(a) foundation in chop-conical

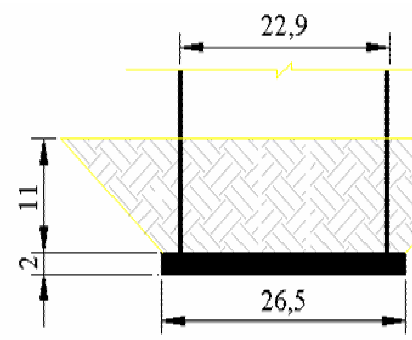

(b) flat foundation

Figure 4: Cross-section of the foundations (measures in meter).

Concrete class $\mathrm{C} 30$ with, with fck $=30 \mathrm{MPa}$, initial modulus of elasticity $\mathrm{E}=30 \mathrm{GPa}$ and Poisson coefficient $\mu=0,20$ was adopted. The steel used in reinforcement of the structures in concrete, CA-50 steel, has characteristic resistance fyk $=500 \mathrm{MPa}$ and elasticity module equal to $196 \mathrm{GPa}$. For the determination of concrete and reinforcement sections was adopted standard Brazilian code NBR-6118 [22]. It was considered reinforcement cover equal to $3 \mathrm{~cm}$ for foundation, opening of cracks limited to maximum value $w \mathrm{k}=0.2 \mathrm{~mm}$. The soil, as indicated by geotechnical investigations conducted on site, consists 
of an initial layer of 3 meters thick composed of moderately compacted silt-clay, followed by a layer of soft silt-clay with 6 meters thick. Under this last layer, lies a layer in clay very hard and compacted. The level of the water was not found.

Figure 5 presents the mesh considered in the simulation of the semi-infinite environment. The discretization of model was made by approximately 6 million of 3D elements, totaling up 204 million degrees of freedom. The analyses were conducted considering parallel processing in PCs cluster according domains decomposition paradigm. The entire mesh was partitioned in nine subdomains, that were executed in independent CPUs, adopting the Conjugated Gradient with Jacob Precondition (PCG) algorithm in the resolution of the resultant algebraic system. In the Figure 6 and 7 are presented the results of vertical displacement of the foundations (post-processed through commercial software in the viewing of the results), obtained from the numerical analyses performed in cluster of PCs. Table 2 presents a summary of the quantitative involved in the execution of the foundations, as well as the results of foundation displacement.

\section{Conclusions}

The results obtained of the case study (Table 2), composed by the foundation of a cylindrical vertical silo with $30.000 \mathrm{t}$, showed that the consumption of steel was reduced by $23 \%$ of the initial value while the consumption of structural concrete was reduced to about $60 \%$. Such difference does not cause surprise; therefore while a foundation plan element suffers efforts of bending moments when subject to a vertical load, including its self-weight, the foundation in conical shell maintains the load applied, primarily of necessities related to the behavior of shell (compression and traction or shear, all they acting inside the plan of the surface). In the conical structures, even when present, the efforts of bending assume barely values of secondary importance.

Table 1: $\quad$ Variation of the physical properties of soil with the depth.

\begin{tabular}{|c|c|c|c|c|c|}
\hline Depth (m) & NSPT & $\begin{array}{c}\text { Module of elasticity } \\
(\mathrm{MPa})\end{array}$ & $\begin{array}{c}\text { Coefficient of } \\
\text { Poisson }\end{array}$ & $\begin{array}{c}\text { Angle of } \\
\text { internal friction }\end{array}$ & $\begin{array}{c}\text { Cohesion } \\
(\mathrm{MPa})\end{array}$ \\
\hline 1 & 28 & 7,00 & 0,35 & 45 & 0,20 \\
2 & 28 & 7,00 & 0,35 & 45 & 0,20 \\
3 & 34 & 8,50 & 0,30 & 50 & 0,30 \\
\hline 4 & 4 & 1,00 & 0,40 & 40 & 0,20 \\
\hline 5 & 5 & 1,25 & 0,40 & 40 & 0,20 \\
\hline 6 & 8 & 2,00 & 0,40 & 40 & 0,20 \\
\hline 7 & 11 & 2,75 & 0,40 & 40 & 0,20 \\
\hline 8 & 10 & 2,50 & 0,40 & 40 & 0,20 \\
\hline 9 & 12 & 3,00 & 0,40 & 45 & 0,20 \\
\hline 10 & 16 & 4,00 & 0,30 & 45 & 0,20 \\
11 & 24 & 6,00 & 0,30 & 50 & 0,03 \\
\hline 12 & 27 & 6,75 & 0,30 & 50 & 0,03 \\
\hline 13 & 36 & 9,00 & 0,30 & 50 & 0,03 \\
\hline 14 & 40 & 10,00 & 0,30 & 50 & 0,03 \\
15 & 57 & 14,25 & 0,30 & 50 & 0,03 \\
\hline
\end{tabular}


Clearly, any structure will take shape only when the construction materials are combined with the workforce. Therefore the economy about the material reduction should be confronted to the increase in the quantity of labor and/or necessary equipment for excavation and landfill. It should be remembered also that even when the total quantity of excavation for execution of the foundations in shell be equal or even smaller than for flat structures, the unit cost of the work by quantity of material is bigger for the shell structures, in function of the its geometrical complexity. Taking into account the two factors mentioned above, it can be affirmed that the adoption of the cone-reversed shell surface will be economically viable whenever the economy about the cost of the material (concrete and steel) exceed the extra cost by the earthwork.
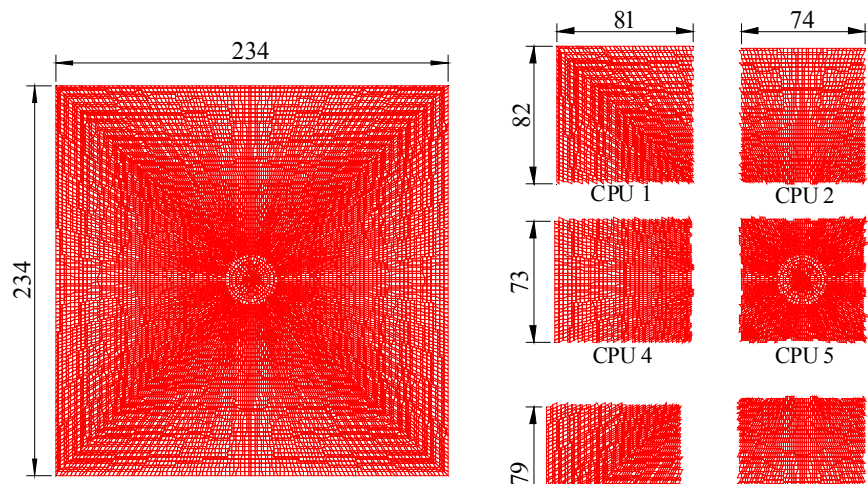

CPU 5
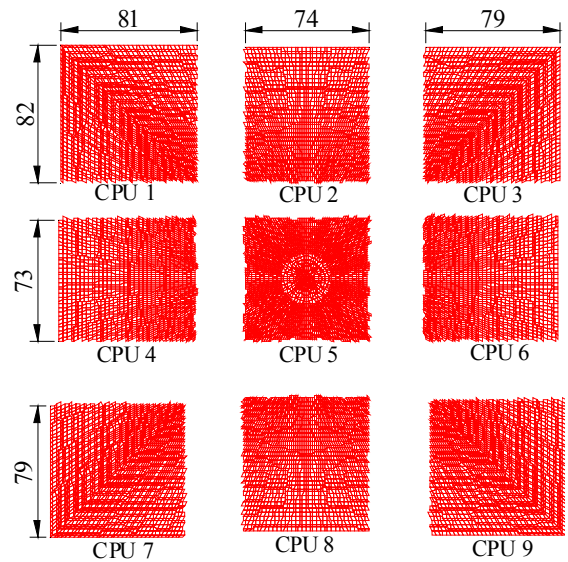

Figure 5: $\quad$ Upper sight of the mesh FEM and Domain Decomposition.

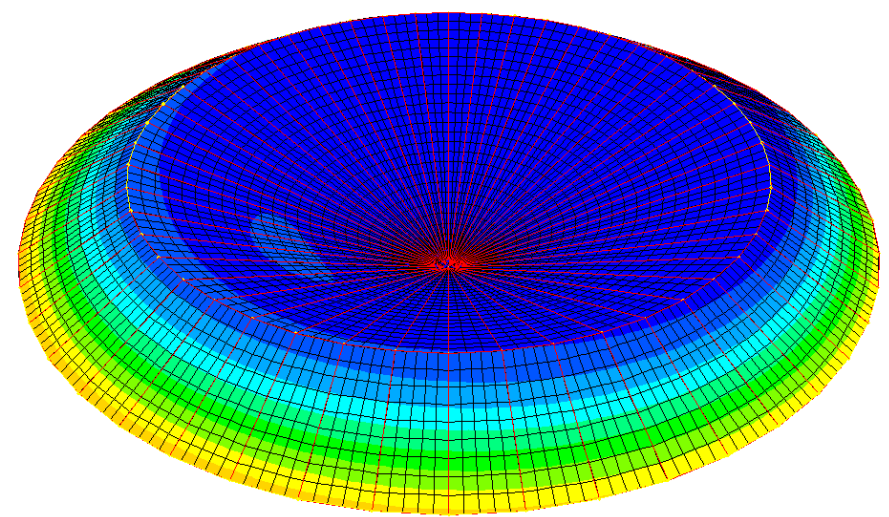

Figure 6: Foundation in shell: vertical displacement (measured in millimeters). 
In relation to the differential displacement, since plan foundation is very rigid it does not present this type of deformation while conical shell suffered $9 \mathrm{~mm}$, corresponding to an angular distortion of about $\mathrm{L} / 30000$, value with negligible impact on performance of the silo. Finally, in this work it can be shown with no doubts that the adoption of the inverted cone led to reduction in overall structure cost, because the reduction in consumption of inputs (concrete and steel) is certainly greater than the increase in consumption of labor.

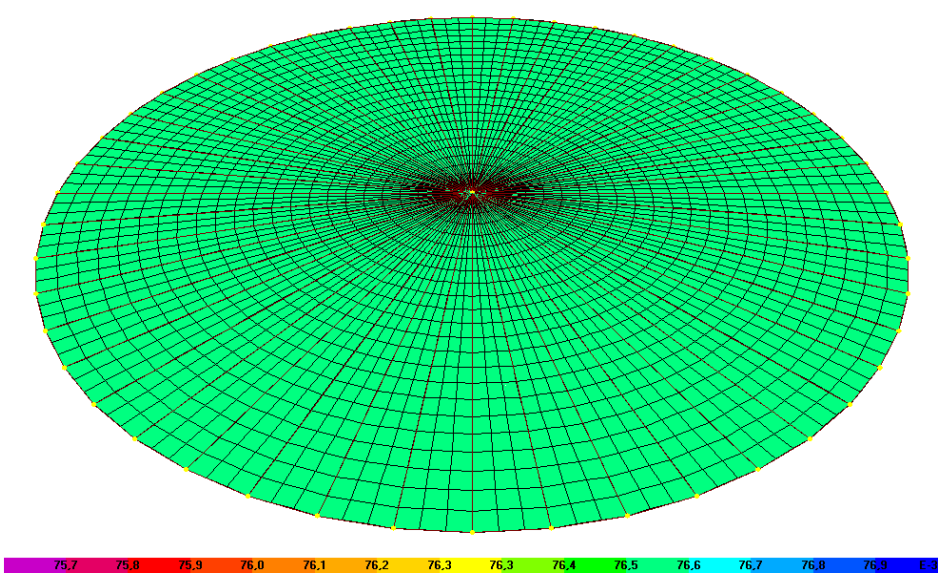

Figure 7: Flat foundation: vertical displacement (measured in millimeters).

Table 2: $\quad$ Comparative chart between proposals.

\begin{tabular}{|l|l|}
\hline \multicolumn{1}{|c|}{ Foundation in shell } & \multicolumn{1}{c|}{ Flat Foundation } \\
\hline Concrete $\mathrm{C} 30=671,9 \mathrm{~m}^{3}$ & Concrete $\mathrm{C} 30=1136,6 \mathrm{~m}^{3}$ \\
\hline Reinforcement $=705,7 \mathrm{t}$ & Reinforcement $=2973 \mathrm{t}$ \\
\hline Forms $=77,8 \mathrm{~m}^{2}$ & Forms $=170 \mathrm{~m}^{2}$ \\
\hline Cushion concrete $=83,9 \mathrm{~m}^{3}$ & Cushion concrete $=56,8 \mathrm{~m}^{3}$ \\
\hline Excavation $=2443 \mathrm{~m}^{3}$ & Excavation $=3175 \mathrm{~m}^{3}$ \\
\hline Landfill $=1771 \mathrm{~m}^{3}$ & Landfill $=2495 \mathrm{~m}^{3}$ \\
\hline $\begin{array}{l}\text { Maximum displacement }=71 \mathrm{~mm} \\
\text { Differential displacement }=9 \mathrm{~mm}\end{array}$ & $\begin{array}{l}\text { Maximum displacement }=76,4 \mathrm{~mm} \\
\text { Differential displacement }=\text { null }\end{array}$ \\
\hline
\end{tabular}

\section{Acknowledgement}

The authors thank to the FAPEMIG for the financial support.

\section{References}

[1] Terzaghi, K. and Frolich, O.K., 1936. Theorie der setzung von tonschichten, F. Deuticke. 
[2] Skempton, A.W. and MacDonald, D.H., 1956. The allowable settlement of buildings, in Proc. of Institute of Civil Engineering, 5, Part III.

[3] Taylor, D.W., 1948. Soil mechanics, Willey International Edition, John Willey e Sons.

[4] Kurian, N.P., 1982. Modern foundations-Introduction of advanced techniques, Tata McGraw-Hill, New Delhi.

[5] Martins, C. J.; Figueiredo; O.A., Peixoto, R.A.F.; Martins, L.A , 2008. A Study of Foundations in Low Bearing Capacity Soil Using a Hyperbolic Paraboloid Shell. In: The Sixth International Conference on Engineering Computational Technology, Athens, p. 1-16.

[6] Kurian, N.P., 2006. Shell foundations - Geometry, analysis, design and construction, Alpha Science International Ltd.

[7] Flugge, W., 1973. Stresses in shells, New York Springer-Verlag.

[8] Candela, F., 1955. Structural applications of hyperbolic paraboloidal shells, Journal of the American Concrete Institute, vol 26, 5, 397-415.

[9] Kurian, N.P., 1977. Economy of hyperbolic paraboloidal shell footings. Geotech. Eng., 8: 53-59.

[10] Hanna, A.M. and Abdel-Rahman, M.M., 1990. Ultimate bearing capacity of triangular shell strip footings on sand, Journal of Geotechnical Engineering, ASCE, Vol.116, No.12 pp. 1851-1863.

[11] Maharaj, D.K., 2003. Nonlinear Finite Element Analysis of Strip Footing on Reinforced Clay, Electronic Journal of Geotechnical Engineering, Vol. 8, Bundle C, Paper 2003-0338

[12] Nicholls, R.L. and Izadi, M.V., 1968. Design and testing of cone and hypar footings, Journal of Soil Mechanics and Foundation Engineering, ASCE, Vol. 94, No. SM1, pp. 47-72

[13] Melerski, E., 1988. Thin shell foundation resting on stochastic soil, Journal of Structural Engineering, Vol.114, No.12, pp. 2692-2709

[14] Kurian, N. P. and P. C. Varghese, 1969. Discussion of "Design and testing of cone and hypar footings," by D. L. Nicholls, and M. V. Izadi. Journal of Soil Mechanics and Foundation Engineering, ASCE, 95(SM1): 415-416

[15] Kurian, N. P. and C. S. Mohan, 1981. Contact pressures under shell foundations, Proceedings of the 10th International Conference on Soil Mechanics and Foundation Engineering, Stockholm, Sweden, Vol. 2, pp. 15-168

[16] K.O. Harrop-Williams and D. Grivas, "Interference between geotechnical structures", Journal of Geotechnical Engineering, vol. 111, no.3, pp. 412464, 1985

[17] Chandrashekhra, K. and Antony, S.J., 1996. Interaction analysis of strip footing resting on a non-homogeneous elastic medium, Computers and Structures, Vol.60, No.1, pp.79-86

[18] Kurian, N. P., 2003. Shell foundations-rationale and use, International eConference on Modern Trends in Foundation Engineering: Geotechnical Challenges and Solutions, 21-26 January, to be Organised by Geotechnical Engineering Division, Department of Civil Engineering, Indian Institute of Technology, Madras, Chennai-600036, India, pp. 1-18. 
[19] Martins C.J., Araújo F.C., Mansur W.J., 2002. An efficient BE iterativesolver-based substructuring algorithm for 3D time-harmonic problems in elastodynamics, Engineering Analysis with Boundary Elements.

[20] Hanna, A.M. and M. Abdel-Rahman, 1998. Experimental investigation on shell foundations on dry sand. Can. Geotech. J., 35: 828-846.

[21] Lemaitre, J. and Chaboche, J. L., 1994. Mechanics of solid materials. Cambridge University Press.

[22] NBR-6118, 2003. Projeto e execução de obras de concreto armado, ABNT. 